\title{
Genetic divergence among populations of the white grub beetle, Dasylepida ishigakiensis (Coleoptera: Scarabaeidae), distributed in the southern part of the Ryukyu Islands of Japan, detected from mitochondrial DNA sequences
}

\author{
Masahiko MuraJi, ${ }^{1, *}$ Yoshio Hirai, ${ }^{1, \dagger}$ Toshiharu AKIno, ${ }^{1, \ddagger} \operatorname{Sadao~WAKAMURA}^{1}$ and \\ Norio ARAKAKI ${ }^{2}$ \\ ${ }^{1}$ National Institute of Agrobiological Sciences; Tsukuba, Ibaraki 305-8634, Japan \\ ${ }^{2}$ Okinawa Prefectural Agricultural Research Center; Itoman, Okinawa 901-0336, Japan
}

(Received 23 July 2007; Accepted 25 January 2008)

\begin{abstract}
The white grub beetle, Dasylepida ishigakiensis, was originally known only in the Yaeyama region, including Ishigaki-jima and Iriomote-jima Islands, of the southern part of the Ryukyu Islands, Japan. At the end of the 1990s, a population was discovered to occur abundantly in sugarcane fields in the Miyako region, including Miyako-jima and Irabu-jima Islands, approximately $90 \mathrm{~km}$ northeast of the Yaeyama region. Using specimens collected from these islands, fragments of mitochondrial DNA containing portions of ribosomal RNA, cytochrome c oxidase subunit I, and cytochrome $b$ genes were sequenced. Phylogenetic analyses using the sequences revealed discrete separation into three clades: two comprised exclusively of individuals from Ishigaki-jima and Iriomote-jima, respectively, and the third comprised of individuals from the Miyako region, including both Miyako-jima and Irabu-jima. Separation of the clades by rather long branches suggested that they have been geographically isolated for an evolutionarily long period and indicated that the population in the Miyako region was not established by the recent invasion of insects from the Yaeyama region.
\end{abstract}

Key words: Nucleotide sequence; mitochondrial DNA; phylogenetic analysis; Dasylepida; sugarcane pest

\section{INTRODUCTION}

The white grub beetle Dasylepida ishigakiensis (Niijima et Kinoshita) is distributed in the southern part of the Ryukyu Islands of Japan (Fujioka, 2001). Before a population was discovered to occur abundantly in sugarcane fields in the Miyako region (Miyako-jima and Irabu-jima Islands) in 1997 (Sadoyama et al., 2001), this species was long considered to be rather rare, occurring only in the natural forests of the Yaeyama region (Ishigakijima and Iriomote-jima), approximately $90 \mathrm{~km}$ southwest of the Miyako region (Hirai, 2001). In the Miyako region, its larval stage causes considerable economic damage to the sugarcane crop
(Sadoyama et al., 2001).

In addition to their different habitats and larval food preferences, differences between the Miyako and Yaeyama populations have been detected in male body color, body length, and cuticular hydrocarbon profile (Hirai et al., 2008); however, it is not clear whether such differences are due to genetic differences between the populations or to phenotypic differences responding to environmental differences between the regions. Thus, the question of whether the Miyako population was established by insects that migrated from the Yaeyama region remains unanswered.

In recent years, entomologists have increasingly used DNA markers to analyze phylogenetic rela-

\footnotetext{
* To whom correspondence should be addressed at: E-mail: mmuraji@affrc.go.jp

${ }^{\dagger}$ Present address: Sena 7-12-11, Aoi-ku, Shizuoka 420-0911, Japan

* Present address: Kyoto Institute of Technology, Kyoto 606-8585, Japan

DOI: 10.1303/aez.2008.287
} 
tionships among local populations. Such analysis will surely be useful for $D$. ishigakiensis, whose populations are separated among islands. In this study, we examined nucleotide sequences of mitochondrial DNA (mtDNA) using individuals collected from the four islands, Miyako-jima, Irabujima, Ishigaki-jima, and Iriomote-jima. The results of phylogenetic analyses revealed that they were divided into three groups that have been genetically isolated for a long period. Based on these results,

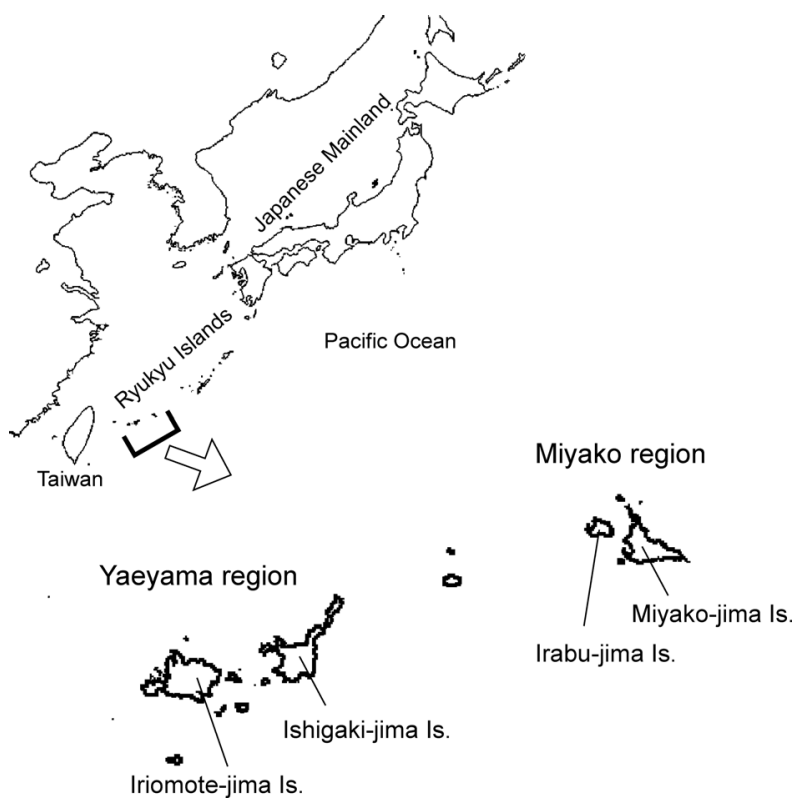

Fig. 1. Map showing localities where the materials were collected. we discuss the causes of genetic divergences and the origin of the population recently discovered in the Miyako region.

\section{MATERIALS AND METHODS}

The materials used in this study are listed in Table 1. Specimens were captured on the islands of Miyako-jima, Irabu-jima, Ishigaki-jima, and Iriomote-jima (Fig. 1) using an insect net. Template DNA was extracted from the legs of individuals using a GenomicPrep Cell \& Tissue DNA Isolation Kit (Amersham Biosciences, Buckinghamshire, UK) and dissolved in $200 \mu \mathrm{l}$ sterilized distilled water

PCR primers used in this study are listed in Table 2. Three sets of universal primers, $16 \mathrm{Fa} /$ 12Rb, UMT10603F/UMT11388R, and C1-J-2195/ AAMT3038R, were used for amplification and sequencing of the mtDNA fragment from the $16 \mathrm{~S}$ ribosomal RNA gene (16S rDNA) to $12 \mathrm{~S}$ rDNA, and portions of the cytochrome $b$ gene (cyt $b$ ), and the cytochrome oxydase subunit I gene (COI), respectively. Amplification was carried out in a $20 \mu \mathrm{l}$ volume containing $1.0 \mu \mathrm{l}$ of DNA template, $1.0 \mu \mathrm{l}$ of each primer $(5 \mathrm{pmol} / \mu \mathrm{l}), 2.0 \mu \mathrm{l}$ of $10 \times$ PCR buffer, $1.6 \mu \mathrm{l}$ of dNTPs (2.5 mM each), and 0.12 units of Ex-Taq DNA polymerase (TaKaRaBio, Otsu, Japan). Temperature cycling was carried out in a Program Temp Control System PC-805 (Astec Co., Ltd., Fukuoka, Japan). After a heating

Table 1. Materials used in this study

\begin{tabular}{|c|c|c|c|c|}
\hline Localities & Date & $n^{\mathrm{a}}$ & Code & Collection \\
\hline \multicolumn{5}{|l|}{ Yaeyama region } \\
\hline \multicolumn{5}{|l|}{ Ishigaki-jima Island } \\
\hline Takeda Rindo, Hirae, Ishigaki City & 2000. III. 20-21 & $4(2)$ & ISG a & T. Fukaishi \\
\hline Takeda Rindo, Hirae, Ishigaki City & 2003. III. 13 & $4(3)$ & ISG b & K. Kohno, Y. Hirai \\
\hline Takeda Rindo, Hirae, Ishigaki City & 2004. III. 10 & $2(1)$ & ISG c & K. Kohno \\
\hline \multicolumn{5}{|l|}{ Iriomote-jima Island } \\
\hline Komi, Taketomi Town & 2004. III. 10 & $6(3)$ & IRM a & Y. Hirai, K. Takahashi \\
\hline Uehara, Taketomi Town & 2004. III. $11-12$ & $1(0)$ & IRM b & Y. Hirai \\
\hline \multicolumn{5}{|l|}{ Miyako region } \\
\hline \multicolumn{5}{|l|}{ Miyako-jima Island } \\
\hline Jimori, Hirara, Miyakojima City & 2000. III. 1 & $3(1)$ & MYK a & N. Arakaki \\
\hline Nobarugoshi, Hirara, Miyakojima City & 2003. II. $7-10$ & $3(1)$ & MYK b & Y. Hirai \\
\hline Gusukube, Miyakojima City & 2004. II. 9-14 & $2(2)$ & MYK c & Y. Hirai \\
\hline \multicolumn{5}{|l|}{ Irabu-jima Island } \\
\hline Irabu, Miyakojima City & 2000. III. 8 & $4(3)$ & IRB & Y. Hirai \\
\hline
\end{tabular}

\footnotetext{
${ }^{a}$ Numbers in parentheses indicate the number of individuals used for sequencing the COI and cyt $b$ fragments.
} 
Table 2. PCR primers used in this study shown in $5^{\prime}-3^{\prime}$ direction

$\begin{array}{llllll}\begin{array}{l}\text { 16S-12S rDNA } \\ 16 F a\end{array} & \text { CCG GTT TGA ACT CAG ATC ATG } & \text { (Muraji and Nakahara, 2001) } \\ \text { 12Rb } & \text { AAC TAG GAT TAG ATA CCC TA } & \text { (Muraji and Nakahara, 2001) } \\ \text { DIMT13350F } & \text { TCA ACT CCT CAT TGG GCA GGC TAG } & \text { (present study) } \\ \text { DIMT14111R } & \text { AAG TTA GTT GTG TGA ATC AGT } & \text { (present study) } \\ \text { cyt } b & & & & & \text { (present study) } \\ \text { UMT10603F } & \text { CTT GAT GAA ATT TTG GAT C } & \text { (Muraji et al., 2000) } \\ \text { UMT11388R } & \text { CTC CTC CTA ATT TAT TAG GAA TTG } & \\ \text { COI } & & & & \text { (Simon et al., 1994) } \\ \text { C1-J-2195 } & \text { TTG ATT TTT TGG TCA TCC AGA AGT } & \text { (Muraji et al., unpublished) } \\ \text { AAMT3038R } & \text { TCC ATT GCA CTA ATC TGC CAT ATT AG }\end{array}$

The sequence of UMT10603F was designed as described in Muraji et al. (2000), and that of AAMT3038R was based on reported sequences of the Anomala species (AB330384-AB330391). The number included in the name of the DIMT, UMT, and AAMT series of primers refers to the nucleotide position in the Drosophila yakuba total mtDNA sequence (Clary and Wolstenholme, 1985) corresponding to the $5^{\prime}$ end of the primer.

step at $92^{\circ} \mathrm{C}$ for $2 \mathrm{~min}$, samples were incubated for 35 cycles of $92^{\circ} \mathrm{C}$ for $1 \mathrm{~min}, 50^{\circ} \mathrm{C}$ for $30 \mathrm{~s}$, and $72^{\circ} \mathrm{C}$ for $2 \mathrm{~min}$. Purification, labeling, and sequencing of the amplified products were performed as described in Muraji and Nakahara (2001). Two additional primers, DIMT13350F and DIMT14111R, designed based on the sequences obtained in this study, were used for sequencing. The sequences of several individuals were submitted to DDBJ/ EMBL/GenBank nucleotide sequence databases (Accession numbers: AB332100-AB332111).

Nucleotide sequences were aligned using Genetyx-Mac ver. 10 (Genetyx Co., Tokyo, Japan) and modified by manual optimization. The aligned sequences were analyzed using MEGA software ver. 3.1 (Kumar et al., 2004) to compute basic statistical data and to generate phylogenetic trees based on the neighbor-joining method. The aligned sequences were also analyzed using PAUP* ver. $4.0 \mathrm{~b} 10$ (Swofford, 2003) to generate phylogenetic trees based on the maximum parsimony method. This analysis was performed using a heuristic search procedure with TBR swapping and 100 max tree options.

\section{RESULTS}

Mitochondrial DNA sequences, including portions of the $16 \mathrm{~S}$ and $12 \mathrm{~S}$ rDNA, and tRNA ${ }^{\mathrm{Val}}$, were determined for $29 \mathrm{D}$. ishigakiensis. Their length varied from $1,608 \mathrm{bp}$ to $1,610 \mathrm{bp}$, and the nucleotide composition was biased to A and $\mathrm{T}$ (average $\mathrm{A}+\mathrm{T} \%=77.5$ ). A $1,610 \mathrm{bp}$-long data set gen- erated by aligning the sequences showed 78 polymorphic sites, 71 of which were parsimony-informative.

In parsimony analysis, two shortest trees were detected. In these trees, sequences were discretely divided into three clades that were highly supported by bootstrap analysis (Fig. 2). Of these, two clades were exclusively composed of insects from Ishigaki-jima and Iriomote-jima, respectively, while the remaining clade included insects from both Miyako-jima and Irabu-jima. Between the shortest trees, the only difference detected was the positioning of sequence ISGc1. The same topology, in terms of sequence grouping, was obtained from neighbor-joining analyses using various distance methods implemented in MEGA.

Using 16 individuals representing the four islands, 788 and $721 \mathrm{bp}$-long sequences containing portions of COI and cyt $b$, respectively, were determined. The sequences were more variable than the rDNAs, and 76 variable sites were detected in each fragment. Neighbor-joining and parsimony analyses of the two data sets produced the same topology as shown in Fig. 2, in terms of sequence grouping (data not shown). The grouping in these analyses was supported by bootstrap values higher than $99 \%$.

By combining the sequences of the three mtDNA regions obtained from the same individuals, 3,123 bp-long sequences were obtained for 16 insects. The phylogenetic trees generated using these sequences evidenced the same topology as shown in Fig. 2, and their topology was strongly 


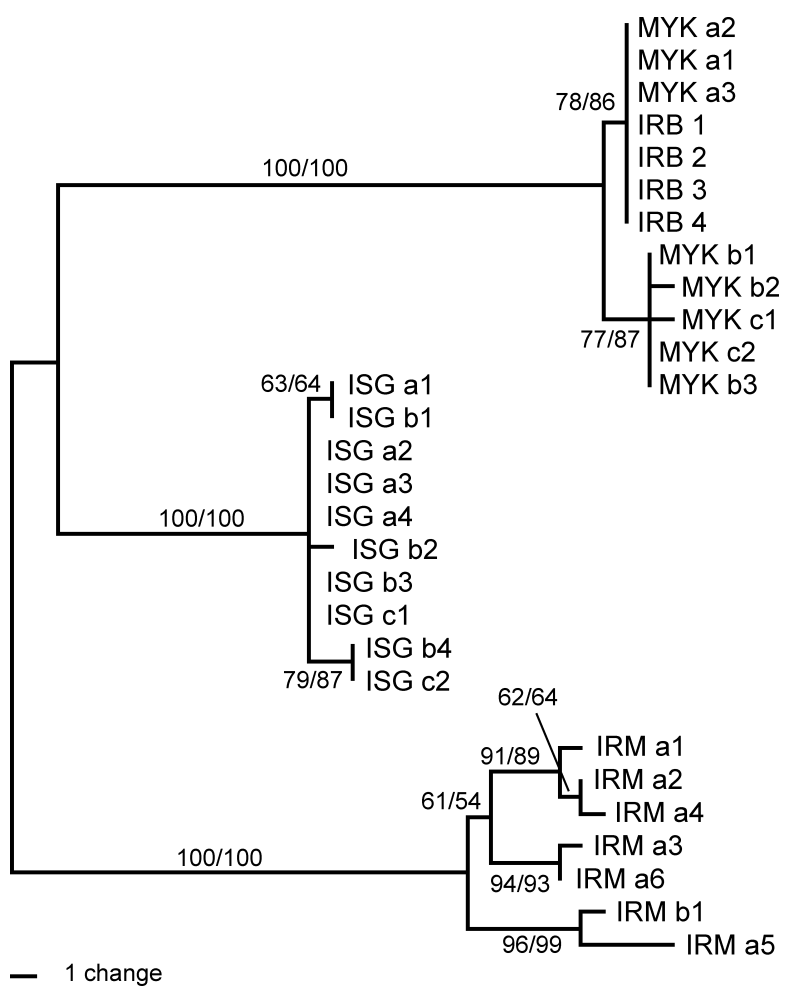

Fig. 2. One of the two most parsimonious trees obtained from maximum parsimony analysis of the $1,610 \mathrm{bp}$-long mtDNA sequence from the $16 \mathrm{~S}$ to $12 \mathrm{~S}$ rDNA (length: 87 ; CI: 0.920; RI: 0.987; RC: 0.908). Bootstrap values higher than $50 \%$ calculated based on 1,000 replications are shown near the branches. The values were calculated using the maximum parsimony method (left) and the neighbor-joining method based on the Jukes-Cantor distances (right).

supported by high bootstrap values (Fig. 3).

\section{DISCUSSION}

In the phylogenetic trees shown in Figs. 2 and 3, individuals are divided into three clades. Because the clades are separated by rather long branches, local populations of $D$. ishigakiensis might have been geographically separated for a long period. When the mitochondrial molecular evolutionary clock, 2.3\% per one million years (Brower, 1994), was applied to the combined sequences, a divergence time of 1.5-2.1 million years was estimated from nucleotide substitution rates of $3.6-4.9 \%$, among the three clades. The suitability of applying such a molecular clock, calculated from different insect groups using various molecular data, to $D$. ishigakiensis is obviously questionable. Nevertheless, the estimation indicates that the population

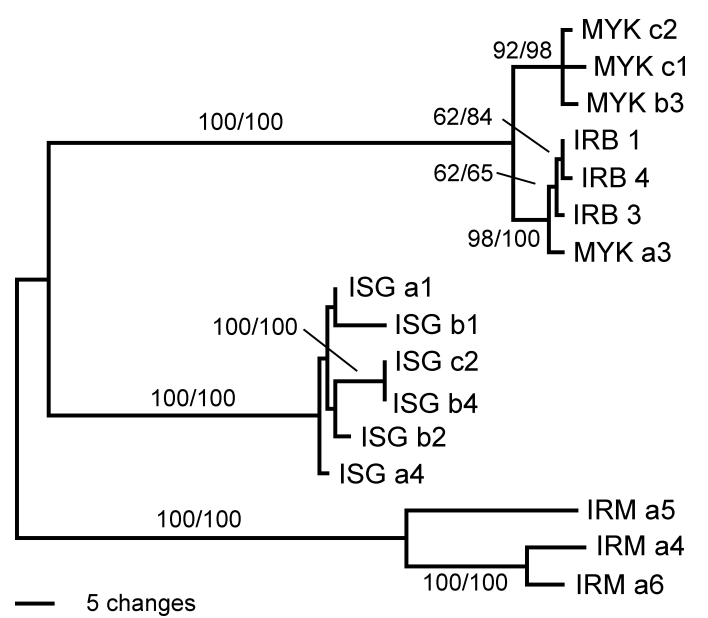

Fig. 3. One of the two most parsimonious trees obtained by maximum parsimony analysis of the $3,123 \mathrm{bp}$-long combined sequence (length: 260; CI: 0.912; RI: 0.970; RC: 0.885). Bootstrap values were calculated and are shown as in Fig. 2.

in the Miyako region was not established by the recent invasion of insects from the Yaeyama region and suggests that they have been genetically isolated during their evolutionary history.

The causes of genetic divergences of terrestrial animals in the Ryukyu Islands have been discussed in relation to paleogeography (Ota, 1998); however, in the case of $D$. ishigakiensis, genetic divergence cannot be fully explained by the paleo-land configuration postulated in this area. Comprehensive hypotheses on paleogeography suggest the emergence of large paleo-islands connecting the islands between the Yaeyama and Miyako regions (Kimura, 1996, 2002) or connecting islands within each region (Kizaki and Oshiro, 1980; Ota, 1998) during the late Pleistocene. It seems difficult for insects to have attained rather high nucleotide substitution rates $(3.6-4.9 \%)$ within the short period after the last land connection. Therefore, the present study suggests that the putative land connection had no influence on the intermingling of local populations of $D$. ishigakiensis, especially between Iriomote-jima and Ishigaki-jima Islands within the Yaeyama region.

One possible explanation for this phenomenon concerns the paleo-climate and vegetation. Studies on pollen assemblages (Kuroda and Ozawa, 1996) suggested diminishing forests of broadleaf evergreen trees, the original habitat of $D$. ishigakiensis supposed from the Ishigaki-jima and Iriomote-jima populations (Hirai, 2001), due to the arid climate in 
the Ryukyu Islands during the last glacial period. Wide development of ancient dunes has also been postulated in this period (Kuroda and Ozawa, 1996). Under such situations, habitats of $D$. ishigakiensis might be separated into different paleoregions. Because the flight activity of this species is restricted both temporally and spatially (Arakaki et al., 2004), the local populations might not have been connected even during periods of land connection.

Although the present study showed relationships among local populations of $D$. ishigakiensis, two major questions about this species remain unanswered: 1) Why did the species become a sugarcane pest only in the Miyako region? and 2) Why was the species not recorded in the Miyako region before the 1990s when the population was first recognized as a sugarcane pest? Before performing a series of studies to answer these questions, it is inevitable to examine the possibility that the population might have diverged in other regions and then been introduced into the Miyako region by human activity. Because the genus Dasylepida includes six other species distributed mainly in tropical and subtropical Asia, such as China, Vietnam, and Taiwan (Fujioka, 2001), future studies must examine the phylogenetic positioning of the three clades among these other Dasylepida species. In addition, detailed studies on morphology are also needed to reconfirm the taxonomic status of the insular populations of this species.

The present study indicated that the mtDNA of the Miyako population is different from those of the Yaeyama region; however, because mtDNA represents only the maternal lineage, further analyses using nuclear DNA markers are needed to examine whether the male adults dispersed between the regions. Results of these studies could also be used to predict the future status of the Yaeyama populations as pests of the sugarcane crop, which is extensively cultivated over a large area in both the Miyako and Yaeyama regions. At present, the populations have not caused damage to the sugarcane crop in the Yaeyama region.

\section{ACKNOWLEDGEMENTS}

We thank T. Fukaishi of Ishigaki City, K. Takahashi of Ushiku City, and K. Kohno of the National Institute of Vegetable and Tea Science for their cooperation with the collection of the beetles, and M. Fujioka of the Tokyo Prefecture for providing useful information. This study was supported in part by a Grant-in-Aid for Scientific Research from the Ministry of Education, Culture, Sports, Science and Technology of Japan to M.M. (No. 19580058).

\section{REFERENCES}

Arakaki, N., Y. Sadoyama, M. Kishita, A. Nagayama, A. Oyafuso, M. Ishimine, M. Ota, T. Akino, M. Fukaya, Y. Hirai, K. Yamamura and S. Wakamura (2004) Mating behavior of the scarab beetle Dasylepida ishigakiensis (Coleoptera: Scarabaeidae). Appl. Entomol. Zool. 39: 669-674.

Brower, A. V. Z. (1994) Rapid morphological radiation and convergence among races of the butterfly Heliconius erato inferred from patterns of mitochondrial DNA evolution. Proc. Natl. Acad. Sci. USA 91: 6491-6495.

Clary, D. O. and D. Wolstenholme (1985) The mitochondrial DNA molecule of Drosophila yakuba: nucleotide sequence, gene organization, and genetic code. J. Mol. Evol. 22: 252-271.

Fujioka, M. (2001) A List of Japanese Lamellicornia. The Japanese Society of Scarabaeideans, Tokyo. 293 pp. (in Japanese).

Hirai, Y. (2001) A curious scarab beetle Dasylepida ishigakiensis, from Sakishima Islands, Okinawa Prefecture. Saikaku Tsushin 4: 27-32 (in Japanese).

Hirai, Y., T. Akino, S. Wakamura and N. Arakaki (2008) Morphological and chemical comparisons of males of the white grub beetle Dasylepida ishigakiensis (Coleoptera: Scarabaeidae) among four island populations in the Sakishima Islands of Okinawa. Appl. Entomol. Zool. 43: $65-72$.

Kimura, M. (1996) Quaternary paleogeography of the Ryukyu Arc. J. Geography 105: 259-285 (in Japanese with English summary).

Kimura, M. (2002) Paleogeography and Organisms Migration of the Ryukyu Arc. Okinawa Times, Naha. 206 pp. (in Japanese).

Kizaki, K. and I. Oshiro (1980) The origin of the Ryukyu Islands. In Natural History of Ryukyu (K. Kizaki ed.). Tsukiji-Shokan, Tokyo, pp. 8-37 (in Japanese).

Kumar, S., K. Tamura and M. Nei (2004) MEGA3: Integrated software for molecular evolutionary genetics analysis and sequence alignment. Brief. Bioinform. 5: $150-163$.

Kuroda, T. and T. Ozawa (1996) Paleoclimatic and vegetational changes during the Pleistocene and Holocene in the Ryukyu Islands inferred from pollen assemblage. J. Geography 105: 328-342 (in Japanese with English summary).

Muraji, M. and S. Nakahara (2001) Phylogenetic relationships among fruit flies, Bactrocera (Diptera, Tephritidae), based on the mitochondrial rDNA sequences. Insect Mol. Biol. 10: 549-559.

Muraji, M., K. Kawasaki and T. Shimizu (2000) Phylogenetic utility of nucleotide sequences of mitochondrial $16 \mathrm{~S}$ ribosomal RNA and cytochrome $b$ genes in anthocorid bugs (Heteroptera: Anthocoridae). Appl. Entomol. Zool. 35: 293-300. 
Ota, H. (1998) Geographic patterns of endemism and speciation in amphibians and reptiles of the Ryukyu archipelago, Japan, with special reference to their paleogeographical implications. Res. Popul. Ecol. 40: 189-204.

Sadoyama, Y., H. Oroku and H. Nakamori (2001) Injury of sugar cane roots by the white grub, Dasylepida sp. (Coleoptera: Scarabaeidae), in the Miyako Islands. Jpn. J. Appl. Entomol. Zool. 45: 89-91 (in Japanese with English summary).
Simon, C., F. Frati, A. Beckenbach, B. Crespi, H. Liu and P. Flook (1994) Evolution, weighting, and phylogenetic utility of mitochondrial gene sequences and a compilation of conserved polymerase chain reaction primers. Ann. Entomol. Soc. Am. 87: 651-701.

Swofford, D. L. (2003) PAUP*. Phylogenetic Analysis Using Parsimony (*and Other Methods). Version 4. Sinauer Associates, Massachusetts. 